\title{
Increased expression of pituitary tumor-transforming gene (PTTG)-1 is correlated with poor prognosis in glioma patients
}

\author{
NOBUYUKI GENKAI, JUMPEI HOMMA, MASAKAZU SANO, RYUICHI TANAKA and RYUYA YAMANAKA
}

Department of Neurosurgery, Brain Research Institute, Niigata University, 1-757 Asahimachi-dori, Niigata 951-8585, Japan

Received January 3, 2006; Accepted February 23, 2006

\begin{abstract}
Pituitary tumor-transforming gene (PTTG), which is homologous to a mammalian securin, plays a pivotal role in cell transformation and is overexpressed in numerous cancer cell lines and tissues. PTTG functions in the control of mitosis, cell transformation, DNA repair and gene regulation. In the present study, we investigated whether the expression of PTTG1 is correlated with tumorigenicity and prognosis in glioma patients. Expression of PTTG1 was confirmed in three glioma cell lines at the mRNA and protein levels using RT-PCR analysis and Western blotting, respectively. Furthermore, PTTG1 protein was detected in 44 glioma tissue samples using immunohistochemical techniques, markedly increased in highgrade gliomas compared to low-grade gliomas and associated with an unfavorable patient outcome. Moreover, siRNA against the PTTG1 gene inhibited cell proliferation and invasion in glioma cell lines. These data suggest that increased expression of PTTG1 contributes to the tumorigenicity of glioma cells and may be useful as a prognostic marker for glioma patients.
\end{abstract}

\section{Introduction}

Glioblastoma is an ordinary solid tumor with a poor prognosis, and even with recent advances in cancer diagnostic methodologies and treatments, the prognosis for glioblastoma patients worldwide has not improved $(1,2)$. This poor prognosis is attributable to the difficulty associated with early detection as well as a high recurrence rate during post-initial treatment observation periods, and is at least partly due to the lack of reliable tumor markers for, and molecular targets against, glioblastomas.

Correspondence to: Dr Ryuya Yamanaka, Department of Neurosurgery, Brain Research Institute, Niigata University, Asahimachi-dori 1-757, Niigata City 951-8585, Japan

E-mail: ryaman@bri.niigata-u.ac.jp

Abbreviations: bFGF, basic fibroblast growth factor; DAB, 3,3diaminobenzidine; FBS, fetal bovine serum; MEM, minimum essential medium; PBS, phosphate-buffered saline; PCR, polymerase chain reaction; PTTG, pituitary tumor-transforming gene; SDS, sodium dodecyl sulfate

Key words: pituitary tumor-transforming gene 1, glioma, siRNA, prognosis
Pituitary tumor-transforming gene (PTTG), the human homolog of securin, was originally identified in rat pituitary tumor cells by differential mRNA display polymerase chain reaction (PCR) (3). Soon thereafter, the human gene for this proto-oncogene was cloned from the human testis (4). The human PTTG family consists of at least three homologous genes (5). Human PTTG1 is located on chromosome 5q33 (6) and its cDNA encodes a protein of 203 amino acids that is predominantly located in the cytoplasm with partial nuclear localization (7). With the exception of the testis and thymus, the levels of PTTG1 mRNA are either low or undetectable in normal adult human tissues (8). However, PTTG1 expression is highly activated in rapidly proliferating cells and various tumors, such as pituitary $(9-11)$, colon $(12)$, thyroid $(13,14)$, ovarian (15), breast (16), testicular (15) and hematopoietic (17) neoplasms. PTTG1 is a multifunctional human securin with roles in the control of mitosis $(7,18,19)$, cell transformation $(3,8)$, DNA repair $(20)$, gene regulation $(8,21,22)$ and fetal development (23). The PTTG2 gene, which is located on chromosome $4 \mathrm{p} 12$, is expressed in most normal and tumor tissues, while the PTTG3 gene, which is on chromosome $8 \mathrm{q} 13.1$, is only expressed in ovarian tumors and ovarian tumor cell lines $(5,6)$. The detailed mechanism by which PTTG1 induces cellular transformation remains unknown, and the functions of PTTG2 and PTTG3 also remain to be elucidated (5).

In the present study, we investigated the expression of PTTG1 in 44 glioma tissue specimens of different grades, and then examined whether or not increased expression of PTTG1 correlated with patient prognosis.

\section{Materials and methods}

Cell lines and culture. The T98G, ON12 and U251 glioma cell lines were purchased from the Cell Bank of the RIKEN BioResource Center (Tsukuba, Japan) and cultured in minimal essential medium (MEM; Nissui Pharmaceutical Inc., Tokyo, Japan) supplemented with $10 \%$ fetal bovine serum (FBS).

Patient characteristics and tissue samples. A total of 44 glioma tissue samples surgically removed at the Department of Neurosurgery, Brain Research Institute, Niigata University, were investigated. The tumor tissue and normal brain tissue specimens were dissected and immediately frozen at $-80^{\circ} \mathrm{C}$. The patient data are shown in Table I. After surgical resection of their tumors, patients with a high-grade glioma received a course of external beam radiation therapy (standard doses: 
Table I. Patient's characteristics.

\begin{tabular}{lccc}
\hline $\begin{array}{l}\text { Pathological } \\
\text { diagnosis }\end{array}$ & $\begin{array}{c}\text { Number } \\
\text { of cases }\end{array}$ & $\begin{array}{c}\text { Gender } \\
\text { (male/female) }\end{array}$ & $\begin{array}{c}\text { Age } \\
\text { (mean } \pm \text { SD) }\end{array}$ \\
\hline Astrocytoma & 9 & $7 / 2$ & $40.7 \pm 16.2$ \\
$\begin{array}{l}\text { Anaplastic } \\
\text { astrocytoma }\end{array}$ & 9 & $4 / 5$ & $39.6 \pm 15.3$ \\
Glioblastoma & 26 & $17 / 9$ & $53.0 \pm 17.6$ \\
Total & 44 & $28 / 16$ & $48.0 \pm 18.0$ \\
\hline
\end{tabular}

40 Gy to the tumor with 3-cm margins, 20 Gy boost to the whole brain) and nitrosourea-based chemotherapy during the course of the disease. Survival was determined from the date of diagnosis to the patient's death or last visit. The diagnoses were based on World Health Organization (WHO) criteria (24). This study was approved by the Ethics Committee of Niigata University. Informed consent was obtained from all patients.

Extraction of proteins. Stored samples were crushed in liquid nitrogen and homogenized in RIPA buffer [50 mM Tris- $\mathrm{HCl}$ pH 7.4, $1 \%$ Nonidet P-40, $0.25 \%$ deoxycholate, $150 \mathrm{mM}$ $\mathrm{NaCl}, 1 \mathrm{mM}$ EGTA and $0.2 \%$ sodium dodecyl sulfate (SDS)] containing the following kinase, phosphatase and protease inhibitors: $1 \mathrm{mM} \mathrm{NaVO}_{3}, 1 \mathrm{mM} \mathrm{NaF}, 1 \mathrm{mM} \mathrm{Na} \mathrm{MoO}_{4}, 10 \mathrm{nM}$ okadaic acid, $1 \mu \mathrm{g} / \mathrm{ml}$ benzamide and aprotinin (all from Sigma, Tokyo, Japan). Following incubation on ice for $15 \mathrm{~min}$, the supernatants were removed and stored at $-80^{\circ} \mathrm{C}$ until analysis.

Immunoblotting. Aliquots $(100 \mu \mathrm{g})$ of the extracted proteins mixed with sample buffer containing 2-mercaptoethanol were separated by 5-20\% SDS-PAGE (Bio-Rad Laboratories, Hercules, CA) and transferred to a nitrocellulose membrane (Bio-Rad Laboratories). The membrane was blocked with 5\% skim milk in Tris-buffered saline overnight and then incubated with a primary antibody against PTTG1 (Santa Cruz Biotechnology, Santa Cruz, CA). An anti- 3 -actin mouse monoclonal antibody (Santa Cruz Biotechnology) was used as an internal control. Immunodetection was performed using a horseradish peroxidase detection system with ECL plus (Amersham, Tokyo, Japan).

Immunohistochemistry. Five-micron sections of the formalinfixed paraffin-embedded tissue specimens were deparaffinized in xylene and dehydrated in a graded ethanol series, followed by phosphate-buffered saline (PBS). The sections were subjected to antigen retrieval by incubation in $10 \mathrm{mM}$ sodium citrate $(\mathrm{pH} 6.0)$ at $121^{\circ} \mathrm{C}$ for $10 \mathrm{~min}$ and then incubated in $0.3 \% \mathrm{H}_{2} \mathrm{O}_{2}$ to quench the endogenous peroxidase activity. Next, the sections were blocked in $10 \%$ goat serum and incubated with a goat polyclonal anti-PTTG1 antibody (1:20 dilution; Santa Cruz Biotechnology) for $12 \mathrm{~h}$ at $4^{\circ} \mathrm{C}$. After washing, the sections were incubated with an avidinbiotin-peroxidase system (Vectastain Elite ABC kit; Vector

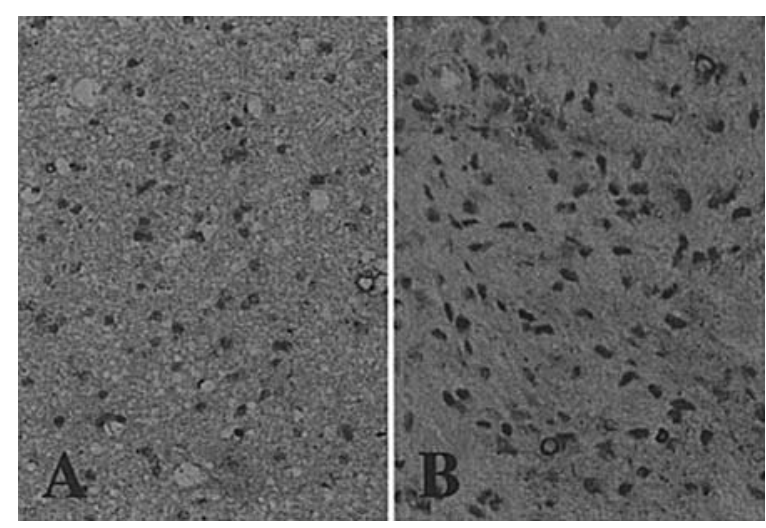

Figure 1. Representative immunohistochemical staining pattern with an antiPTTG1 antibody. (A) Astrocytoma classified as showing low PTTG1 expression. (B) Glioblastoma multiforme classified as showing high PTTG1 expression. Magnification, x200.

Laboratories, Burlingame, CA) and then exposed to $0.01 \%$ 3,3-diaminobenzidine (DAB; Sigma) in PBS containing $0.01 \%$ hydrogen peroxide for $10-20 \mathrm{~min}$. Finally, the sections were examined under a light microscope at an original magnification of $x 400$, and the intensity and area of positive cells were recorded for each immunostained specimen. At this time, the observers were blind to the case numbers. The expression of PTTG1 was evaluated by assigning an immunohistochemical score, defined as the staining intensity $(0$, none; 1 , weak; 2 , moderate; 3 , strong) and the weighted average (sum of points $\mathrm{x}$ area $\%$ ) of the expression.

RNA isolation and quantitative PCR. Total RNA was isolated from the U251 cell line and used as a template for first-strand cDNA synthesis with oligo(dT) primers and reverse transcriptase (SuperScript II RNase H; Life Technologies, Grand Island, NY) according to the manufacturer's instructions. Next, quantitative real-time PCR was performed using a LightCycler (Idaho Technology, Salt Lake City, UT). The PCR solution contained 1X LightCycler DNA Master SYBR-Green I (Roche Molecular Biochemicals, Mannheim, Germany), $0.5 \mu \mathrm{M}$ of each primer, $3 \mathrm{mM} \mathrm{MgCl}_{2}$ and $2 \mu 1$ of cDNA template. The PCR conditions were as follows: 1 cycle of denaturation at $95^{\circ} \mathrm{C}$ for $10 \mathrm{~min}$, followed by 40 cycles of $95^{\circ} \mathrm{C}$ for $15 \mathrm{sec}, 55^{\circ} \mathrm{C}$ for $5 \mathrm{sec}$ and $72^{\circ} \mathrm{C}$ for $10 \mathrm{sec}$. The 352-bp PCR product was then subjected to a post-PCR melting cycle. The intensity of fluorescence was calculated at each cycle, and compared to a standard curve constructed using 4-fold serial dilutions of PTTG1 cDNAs obtained from glioma cell lines. The primer sequences for the PCR amplification were as follows: PTTG1 sense, 5'-AGT TTC AAC ACC ACG TTT TGG C-3'; PTTG1 antisense, 5'-GCT TTT CAA GCT CTC TCT CCT CG-3'.

SiRNA treatment and cell proliferation assay. A specific siRNA directed against human PTTG was purchased from Qiagen Inc. (Tokyo, Japan). For PTTG RNA silencing, we first tested two different siRNA oligonucleotide sequences, designated PTTG1.1 and PTTG1.2 (25). The sense and antisense sequences used were: PTTG1.1: sense, 5'-GAU CUC AAG UUU CAA CAC Ctt-3' and antisense, 5'-GGU GUU 
Table II. Correlation of immunohistochemical pattern and pathological diagnosis.

\begin{tabular}{lcccc}
\hline & 0 , none & 1, weak & 2 , moderate & 3 , strong \\
\hline Astrocytoma & 0 & 5 & 4 & $0-$ \\
$\begin{array}{l}\text { Anaplastic } \\
\text { astrocytoma }\end{array}$ & 1 & 4 & 4 & $0-$ \\
Glioblastoma & 0 & 1 & 17 & $2-$ \\
\hline
\end{tabular}

${ }^{*} \mathrm{P}<0.05$.

GAA ACU UGA GAU Ctc-3'; PTTG1.2: sense, 5'-GUC UGU AAA GAC CAA GG Gatt-3' and antisense, 5'-UCC CUU GGU CUU UAC AGA Ctt-3'. We also used negative control oligonucleotides (Qiagen Inc.) with the following sequences: sense, 5'-AGU ACU GCU UAC GAU ACG Gtt-3' and antisense, 5'-CCG UAU CGU AAG CAG UAG UAC Utt-3'. The siRNAs were introduced into glioma cell lines by cytofectin-mediated transfection (Qiagen Inc.) according to the manufacturer's instructions, and the cells were cultured in 96well plates in $100 \mu \mathrm{l}$ of serum-enriched medium. When the cells reached $80 \%$ confluence, $25 \mu 1$ of $100 \mathrm{nM}$ siRNA in cytofectin was added dropwise to the cell culture. After a further $48 \mathrm{~h}$ of culture, the numbers of viable cells were evaluated by incubation with Tetra Color One (Seikagaku Co., Tokyo, Japan) and the values obtained were compared with those of controls. Control experiments were performed with a Cy3-labeled siRNA directed against an unrelated mRNA (luciferase; siRNA $\mathrm{LuC}_{\mathrm{L}}$; Qiagen). The transfection efficiency was confirmed using the Cy3-labeled siRNA $\mathrm{LUC}_{\mathrm{LC}}$ in each assay. All proliferation experiments were repeated at least twice as independent experiments, and the results are presented as the mean \pm standard deviation (SD) of two independent experiments.

Cell invasion of Matrigel. A Transwell containing an $8 \mu \mathrm{m}$ diameter pore membrane (Becton-Dickinson, Tokyo, Japan) was coated with $500 \mu 1$ of Matrigel (Becton-Dickinson) at $100 \mu \mathrm{g} / \mathrm{ml}$. Cells were either left untreated, or transfected with the control or PTTG1 siRNA as described above. After $24 \mathrm{~h}$ of incubation, the cells were detached with a cell dissociation solution (Sigma), washed twice with PBS and resuspended in MEM containing $10 \%$ FBS. In the case of the siRNA, the cells were subjected to a second transfection $24 \mathrm{~h}$ after the first. In each case, a total of $1 \times 10^{5}$ cells were seeded into the upper Matrigel-coated chamber of the Transwell, while the lower chamber was filled with MEM supplemented with $10 \%$ FBS. After $24 \mathrm{~h}$ of incubation at $37^{\circ} \mathrm{C}$, the non-migrated cells in the upper chamber were gently detached by scraping, while the adherent cells present on the lower surface of each insert were stained with Giemsa and counted in 10 fields by light microscopy at magnification of x200. The results for the control and PTTG1 siRNAs were calculated with reference to the control values observed after incubation of untreated control cells.
Table III. Correlation of immunohistochemical score and pathological diagnosis.

\begin{tabular}{lcccc}
\hline & $0-1$ & $1-2$ & $2-3$ & Mean \pm SD \\
\hline Astrocytoma & 6 & 3 & 0 & $0.65 \pm 0.56$ \\
$\begin{array}{l}\text { Anaplastic } \\
\text { astrocytoma }\end{array}$ & 5 & 4 & 0 & $0.81 \pm 0.66-$ \\
Glioblastoma & 11 & 14 & 1 & $1.17 \pm 0.64$ \\
\hline
\end{tabular}

${ }^{* *} \mathrm{P}<0.05$

Statistics. The differences in PTTG1 expression between the glioma subgroups were tested for statistical significance using the Mann-Whitney U test. Statistical significance was determined at the $\mathrm{P}<0.05$ level. Survival curves were estimated according to the method of Kaplan and Meier and compared using the generalized Wilcoxon test. The log-rank test was used to assess the strength of associations between the survival time and single variables corresponding to factors thought to be prognostic for survival.

\section{Results}

Immunohistochemical analysis of PTTG1 expression in glioma tissue. Immunohistochemistry was carried out to detect the localization of PTTG1 protein in glioma tissue, and the immunostaining pattern is shown in Fig. 1. PTTG1 expression was detected in the nucleus of the tumor cells, revealing that activated transcription factors had translocated into the nucleus. We analyzed the 44 available specimens and investigated the correlations among PTTG1 staining, patient survival and histological grading. Glioblastoma patients (26 cases) showed strong staining in comparison with grade-2 and -3 patients (18 cases) (Table II; $\mathrm{P}=0.03$ ). Similarly, glioblastoma patients showed a high immunohistochemical score compared with grade- 2 and -3 patients (Table III; $\mathrm{P}=0.02$ ). When the high immunohistochemical score group was compared with the low immunohistochemical score group, increased PTTG1 expression was correlated with patient survival in astrocytoma plus anaplastic astrocytoma cases (Fig. 2A; log-rank test, $\mathrm{P}=0.70$ ), anaplastic astrocytoma plus glioblastoma cases (Fig. 2B; log-rank test, $\mathrm{P}=0.01$ ), glioblastoma cases (Fig. 2C; log-rank test, $\mathrm{P}=0.03$ ) and all glioma cases (Fig. 2D; log-rank test, $\mathrm{P}=0.003$ ).

PTTG1 protein expression in glioma cells evaluated by Western blotting. We analyzed the expression of PTTG1 protein in U251, ON12 and T98G cells by Western blotting. As shown in Fig. 3, a 28-kDa product was expressed in all three glioma cell lines. Furthermore, $\beta$-actin protein, which served as a control, was expressed at $42 \mathrm{kDa}$.

PTTG1 mRNA expression is inhibited in glioma cells by PTTG1 siRNA transfection. We compared the expression levels of the PTTG1 gene in U251 cells by quantitative real-time 

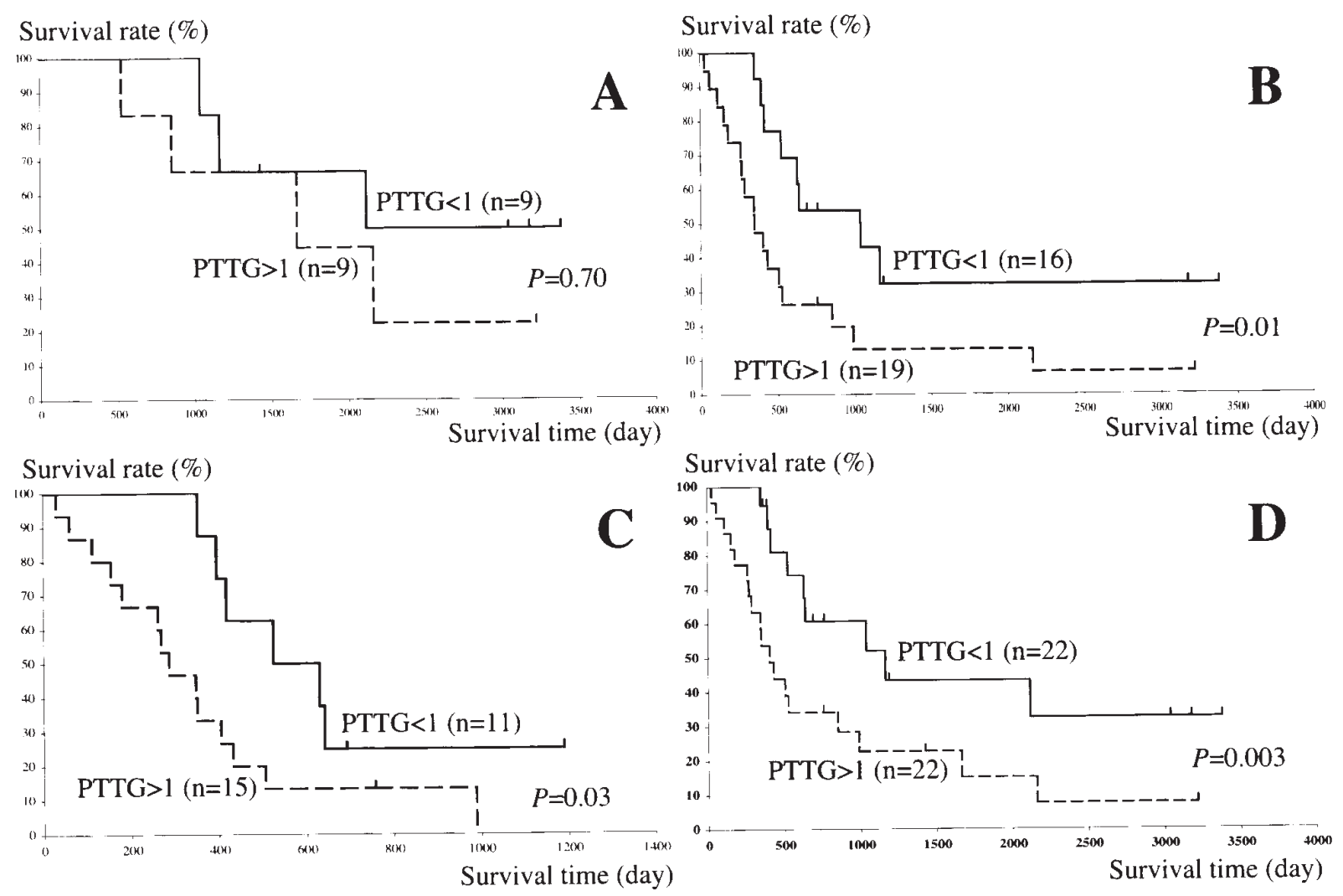

Figure 2. PTTG1 protein expression and patient survival. Kaplan-Meier survival curves for patients who underwent surgical resection of glioma tissue, stratified according to the level of PTTG1 expression in their tumors. A comparison of the protein expression (immunohistochemical score: sum of intensity $\mathrm{x}$ area $\%$ ) and overall survival of the glioma patients is shown. When the high immunohistochemical score group is compared with the low immunohistochemical score group, increased PTTG1 expression is correlated with patient survival in astrocytoma plus anaplastic astrocytoma cases (A: log-rank test, $\mathrm{P}=0.70$ ), anaplastic astrocytoma plus glioblastoma cases (B: log-rank test, $\mathrm{P}=0.01)$, glioblastoma cases (C: log-rank test, $\mathrm{P}=0.03)$ and all glioma cases $(\mathrm{D}$ : logrank test, $\mathrm{P}=0.003)$.

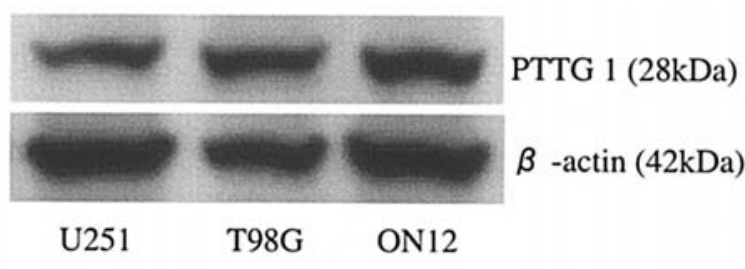

Figure 3. Expression of PTTG1 protein in glioma cell lines detected by Western blotting. In U251, ON12 and T98G cells, a $28-\mathrm{kDa}$ product is expressed. Furthermore, $\beta$-actin protein, which serves as a control, is expressed at $42 \mathrm{kDa}$.

PCR. We synthesized siRNAs that targeted PTTG1 mRNA for degradation following their transfection into cells, thereby reducing the expression of PTTG1 mRNA. We analyzed the efficacy of the siRNA-mediated inhibition of PTTG1 expression in U251 cells. After transfection with the PTTG1 siRNA, the PTTG1 mRNA levels over the ensuing $48 \mathrm{~h}$ were $\sim 16 \%$ of the levels in untreated or control siRNA-treated cells during the same time period (Fig. 4A; $\mathrm{P}<0.05$ ).

Glioma cell proliferation and invasion are inhibited by PTTG1 siRNA transfection. PTTG1 overexpression was linked with the aggressiveness of the glioma in our analysis. In order to determine whether downregulation of endogenous PTTG1 would suppress the proliferation and invasive behavior of gliomas, we used the above-mentioned siRNAs that targeted PTTG1 mRNA for degradation, thereby reducing the expression of PTTG1 protein. The efficacy of the siRNAmediated inhibition of PTTG1 protein synthesis was analyzed in U251, ON12 and T98G cells. After transfection with the PTTG1 siRNA, the U251 cell counts over the ensuing $48 \mathrm{~h}$ were $\sim 60 \%$ of the levels of untreated or control siRNA-treated cells during the same time period (Fig. 4B; $\mathrm{P}<0.05$ ). For invasion assays, the transfectants were seeded onto Matrigelcoated invasion chambers and incubated for $24 \mathrm{~h}$, before the total number of cells on the underside of each filter was determined. As shown in Fig. 4C, transfection of U251 cells with the PTTG1 siRNA inhibited cell invasion through the Matrigel by $>30 \%$, whereas the control siRNA had no effect $(\mathrm{P}<0.01)$. Invading cells were significantly suppressed by the siRNA against PTTG1, as reflected in the observed reductions of mRNA expression. Since the results obtained were virtually identical for all three cell types, only those for one cell type are presented.

\section{Discussion}

Malignant gliomas are the most common primary brain tumors and are generally considered to be one of the deadliest human cancers. Glioblastoma multiforme, which is pathologically the 


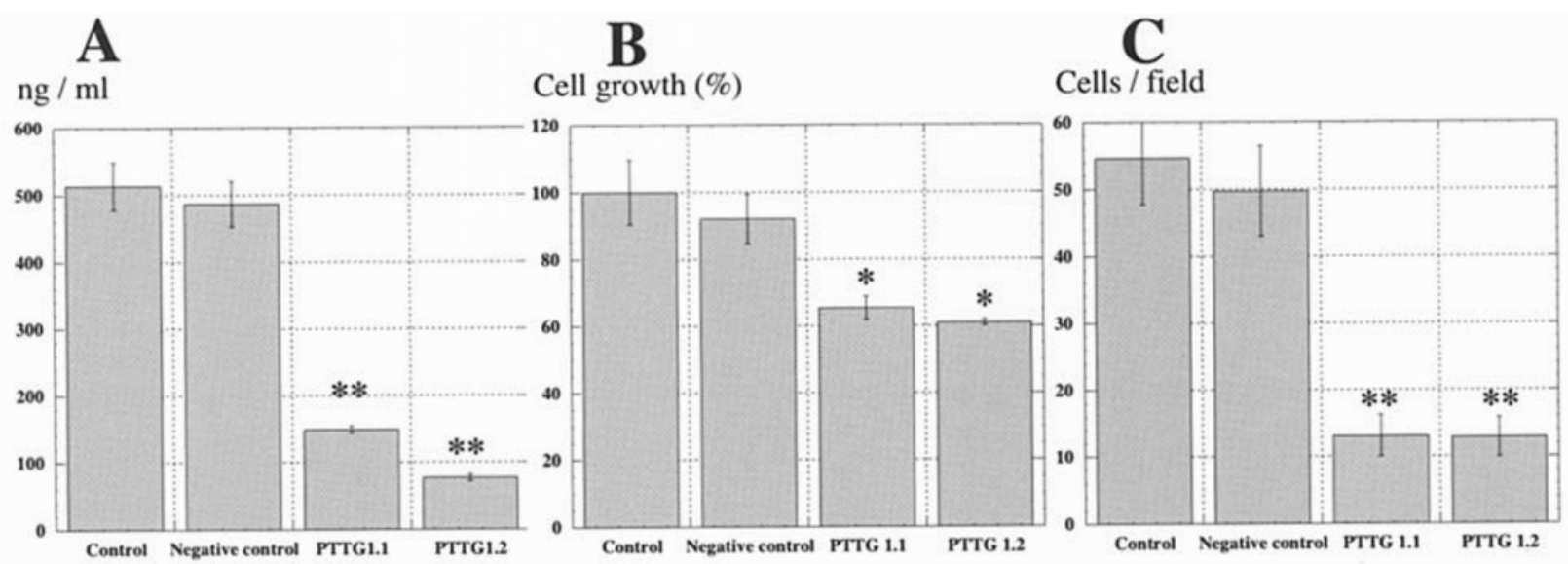

Figure 4. (A) Effects of a PTTG1 siRNA on PTTG1 mRNA expression in human glioma cell lines. After transfection with the PTTG1 siRNA, the PTTG1 mRNA levels over the ensuing $48 \mathrm{~h}$ are significantly suppressed to $\sim 16 \%$ of the levels in the untreated or control siRNA-treated cells during the same time period. (B) Effects of PTTG1 protein knockdown by a PTTG1 siRNA on the proliferation of human glioma cells. U251 cells were transiently transfected with siRNAs and subjected to cell proliferation assays. After transfection with the PTTG1 siRNA, the U251 cell counts over the ensuing $48 \mathrm{~h}$ are approximately $60 \%$ of the levels in the untreated or control siRNA-treated cells during the same time period. ${ }^{*} \mathrm{P}<0.05$ compared with both control groups. (C) For the invasion assays, the transfectants were seeded onto Matrigel-coated invasion chambers and incubated for $24 \mathrm{~h}$, before the total number of cells on the underside of each filter was determined. Invading cells are significantly suppressed by the siRNA against PTTG1, as reflected in the observed reduction of protein expression. ${ }^{* *} \mathrm{P}<0.01$ compared with both control groups.

most aggressive form, has a median survival time of 9-14.6 months $(1,2)$. Advances in the basic knowledge of cancer biology, as well as in surgical techniques, chemotherapy and radiotherapy, have led to little improvement in the survival rates for glioblastoma multiforme (26). Therefore, there is a need to venture along previously unexplored avenues in order to devise more effective therapeutic approaches, define the biological features of glioblastomas more clearly and discover novel target molecules.

Overexpression of PTTG1 has been identified in many cancers as well as in cell lines representing pituitary, colon, thyroid, testicular, ovarian, breast and various other solid tumors. PTTG1 mRNA expression has been reported to serve as a marker for lymph node invasion in colon cancer (12) and tumor recurrence in primary breast cancer (16).

Although the mechanisms involved in PTTG cellular transformation and tumorigenesis remain to be elucidated, several reports have described the role of PTTG1 in tumor progression. First, PTTG1 expression was reported to be cell cycle-dependent, being lowest at the G1-/S-phase border, gradually increasing during S-phase and peaking at the G2/ M-phases (7). PTTG functions as a regulator of separin, an enzyme that degrades cohesin during anaphase, and maintains sister chromatid binding $(18,27)$ to prevent premature chromosome separation through inhibition of separase activity. Overexpression of PTTG induces aneuploidy in live cells via chromatid missegregation (28), enhances cell proliferation, induces cellular transformation and promotes tumor formation in nude mice $(8,29)$. Second, c-myc was reported to be a downstream target for PTTG1. Overexpression of c-myc protein stimulates cell cycle progression, causes transformation, blocks differentiation and induces apoptosis under low-serum conditions (30). Induction of c-myc expression by overexpression of PTTG1 results in increased cell proliferation, thereby supporting the role of PTTG1 in cell growth regulation (31). The MAP kinase cascade and c-Myc have been suggested to be involved in PTTG-mediated cell proliferation. Third, PTTG1 was reported to induce angiogenesis through the angiogenic factor basic fibroblast growth factor (bFGF), which is a significant factor for tumor progression (32).

The relationships between PTTG and the clinical features of gliomas have not previously been described. In the current study, we have presented data concerning the expression of PTTG1 in glioma cell lines and tissues, and shown that PTTG1 protein is overexpressed in high-grade astrocytomas compared to low-grade astrocytomas. On the basis of our data, PTTG1 may potentially play a role in the proliferation and invasiveness of glioma cells. Therefore, PTTG1 may be a novel molecular target for therapy as well as an important predictive marker for survival in glioma patients.

\section{Acknowledgements}

We are grateful to N. Kiyama and F. Higuchi for their excellent technical assistance.

\section{References}

1. Stewart LA: Chemotherapy in adult high-grade glioma: a systematic review and meta-analysis of individual patient data from 12 randomized trials. Lancet 359: 1011-1018, 2002.

2. Stupp R, Mason WP, van den Bent MJ, et al: Radiotherapy plus concomitant and adjuvant temozolomide for glioblastoma. N Engl J Med 352: 987-996, 2005.

3. Pei L and Melmed S: Isolation and characterization of a pituitary tumor-transforming gene (PTTG). Mol Endocrinol 11: 433-441, 1997.

4. Kakar SS: Molecular cloning, genomic organization, and identification of the promotor for the human pituitary tumor transforming gene (PTTG). Gene 240: 317-324, 1999.

5. Chen L, Puri R, Lefkowitz EJ and Kakar SS: Identification of the human pituitary tumor transforming gene (hPTTG) family: molecular structure, expression, and chromosomal localization. Gene 248: 41-50, 2000.

6. Prezant TR, Kadioglu P and Melmed S: An intronless homolog of human proto-oncogene hPTTG is expressed in pituitary tumors: evidence for hPTTG family. J Clin Endocrinol Metab 84: 1149-1152, 1999. 
7. Yu R, Ren SG, Horwitz GA, Wang Z and Melmed S: Pituitary tumor transforming gene (PTTG) regulates placental JEG-3 cell division and survival: evidence from live cell imaging. Mol Endocrinol 14: 1137-1146, 2000.

8. Zhang X, Horwitz GA, Prezant TR, Valentini A, Nakashima M, Bronstein MD and Melmed S: Structure, expression, and function of human pituitary tumor-transforming gene (PTTG). Mol Endocrinol 13: 156-166, 1999.

9. Zhang X, Horwitz GA, Heaney AP, Nakashima M, Prezant TR, Bronstein MD and Melmed S: Pituitary tumor transforming gene (PTTG) expression in pituitary adenomas. J Clin Endocrinol Metab 84: 761-767, 1999

10. McCabe CJ, Khaira JS, Boelaert K, et al: Expression of pituitary tumor transforming gene (PTTG) and fibroblast growth factor-2 (FGF-2) in human pituitary adenomas: relationships to clinical tumour behaviour. Clin Endocrinol (Oxf) 58: 141-150, 2003.

11. Yu R and Melmed S: Oncogene activation in pituitary tumors. Brain Pathol 11: 328-341, 2001.

12. Heaney AP, Singson R, McCabe CJ, Nelson V, Nakashima M and Melmed S: Expression of pituitary-tumour transforming gene in colorectal tumours. Lancet 355: 716-719, 2000.

13. Heaney AP, Nelson V, Fernando M and Horwitz G: Transforming events in thyroid tumorigenesis and their association with follicular lesions. J Clin Endocrinol Metab 86: 5025-5032, 2001.

14. Boelaert K, McCabe CJ, Tannahill LA, et al: Pituitary tumor transforming gene and fibroblast growth factor-2 expression: potential prognostic indicators in differentiated thyroid cancer. J Clin Endocrinol Metab 88: 2341-2347, 2003.

15. Puri R, Tousson A, Chen L and Kakar SS: Molecular cloning of pituitary tumor transforming gene 1 from ovarian tumors and its expression in tumors. Cancer Lett 163: 131-139, 2001.

16. Solbach C, Roller M, Fellbaum C, Nicoletti M and Kaufmann M: PTTG mRNA expression in primary breast cancer: a prognostic marker for lymph node invasion and tumor recurrence. Breast 13: 80-81, 2004.

17. Dominguez A, Ramos-Morales F, Romero F, et al: hpttg, a human homologue of rat pttg, is overexpressed in hematopoietic neoplasms. Evidence for a transcriptional activation function of hPTTG. Oncogene 17: 2187-2193, 1999.

18. Zou H, McGarry TJ, Bernal T and Kirschner MW: Identification of a vertebrate sister-chromatid separation inhibitor involved in transformation and tumorigenesis. Science 285: 418-422, 1999.

19. Zur A and Brandeis M: Securin degradation is mediated by fzy and fzr, and is required for complete chromatid separation but not for cytokinesis. EMBO J 20: 792-801, 2001.
20. Romero F, Multon MC, Ramos-Morales F, Dominguez A, Bernal JA, Pintor-Toro JA and Tortolero M: Human securin, hPTTG, is associated with $\mathrm{Ku}$ heterodimer, the regulatory subunit of the DNA-dependent protein kinase. Nucleic Acids Res 29: 1300-1307, 2001.

21. McCabe CJ, Boelaert K, Tannahill LA, et al: Vascular endothelial growth factor, its receptor KDR/Flk-1, and pituitary tumor transforming gene in pituitary tumors. J Clin Endocrinol Metab 87: 4238-4244, 2002.

22. Pei L: Activation of mitogen-activated protein kinase cascade regulates pituitary tumor-transforming gene transactivation function. J Biol Chem 275: 31191-31198, 2000.

23. Boelaert K, Tannahill LA, Bulmer JN, et al: A potential role for PTTG/securin in the developing human fetal brain. FASEB J 17: 1631-1639, 2003

24. Kleihues P, Louis DN, Scheithauer BW, Rorke LB, Reifenberger G, Burger PC and Cavenee WK: The WHO classification of tumors of the nervous system. J Neuropathol Exp Neurol 61: 215-225, 2002.

25. Tfelt-Hansen J, Yano S, Bandyopadhyay S, Carroll R, Brown EM and Chattopadhyay N: Expression of pituitary tumor transforming gene (PTTG) and its binding protein in human astrocytes and astrocytoma cells: function and regulation of PTTG in U87 astrocytoma cells. Endocrinol 145: 4222-4231, 2004.

26. Maher EA, Furnari FB, Bachoo RM, Rowitch DH, Louis DN, Cavenee WK and DePinho RA: Malignant glioma: genetics and biology of a grave matter. Genes 15: 1311-1333, 2001.

27. Jallepalli PV, Waizenegger IC, Bunz F, et al: Securin is required for chromosomal stability in human cells. Cell 105: 445-457, 2001.

28. Yu R, Lu W, Chen J, McCabe CJ and Melmed S: Overexpressed pituitary tumor-transforming gene causes aneuploidy in live human cells. Endocrinol 144: 4991-4998, 2003.

29. Karkar SS and Jennes L: Molecular cloning and characterization of the tumor transforming gene (TUTR1): a novel gene in human tumorigenesis. Cytogenet Cell Genet 84: 211-216, 1999.

30. Heanriksson M and Luscher B: Proteins of the Myc network; essential regulators of cell growth and differentiation. Adv Cancer Res 68: 109-182, 1996.

31. Pei L: Identification of c-myc as a down-stream target for pituitary tumor-transforming gene. J Biol Chem 276: 8484-8491, 2001.

32. Ishikawa H, Heaney AP, Yu R, Horwitz GA and Melmed S: Human pituitary tumor-transforming gene induces angiogenesis. J Clin Endocrinol Metab 86: 867-874, 2001. 